\title{
Simultaneous Determination and Mutual Interaction Study of Ciprofloxacin and Chloramphenicol in Concomitant Administration by a New UPLC Method
}

\author{
Uddin $\mathbf{M N}^{1 *}$, Das $\mathbf{S}^{2}$, Md Mijan $\mathbf{N H}^{1}$, Md Al-Amin ${ }^{1}$ and Bhuiyan $\mathbf{H R}^{2}$ \\ ${ }^{1}$ Department of Chemistry, University of Chittagong, Chittagong 4331, Bangladesh \\ ${ }^{2}$ BCSIR Laboratories, Chittagong, Bangladesh \\ "Corresponding author: Uddin MN, Department of Chemistry, University of Chittagong, Chittagong 4331, Bangladesh, Tel: 0088-01710915011; E-mail: \\ nasircu72@gmail.com
}

Received date: December 19, 2016; Accepted date: January 20, 2017; Published date: January 23, 2017

Copyright: $\odot 2017$ Uddin MN, et al. This is an open-access article distributed under the terms of the Creative Commons Attribution License, which permits unrestricted use, distribution, and reproduction in any medium, provided the original author and source are credited.

\begin{abstract}
A new simple, fast, accurate, precise and reproducible UPLC method was developed for the simultaneous estimation of ciprofloxacin and chloramphenicol. Reversed-phase Shim-pack XR-ODS $(100 \times 3.0 \mathrm{~mm}, 1.7 \mu \mathrm{m})$ column was used to resolve the drugs utilizing a mixture of $\mathrm{CH}_{3} \mathrm{OH}$ and $5 \mathrm{mM} \mathrm{NaH} \mathrm{PO}_{4}$ as mobile phase at gradient program equilibrated initially by $56: 44(\mathrm{v} / \mathrm{v})$. The mobile phase was pumped at a flow rate of $0.20 \mathrm{~mL} \mathrm{~min}^{-1}$ with detection at $280 \mathrm{~nm}$. $10 \mu \mathrm{L}$ volume of sample was injected by the auto sampler. Separation was completed within $3.82 \pm 0.03$ minutes.

For both drugs linear was obtained over a studied concentration range of $10 \mu \mathrm{g} \mathrm{mL}^{-1}$ with correlation coefficient 0.999. Relative Standard Deviation (RSD) for intra and inter day precision was $<1.5 \%$ indicating the method's good reproducibility. The mean recovery of the drug determination was $99.39 \%$. LOD was found to be $0.025,0.020 \mu \mathrm{g}$ $\mathrm{mL}^{-1}$ for ciprofloxacin and chloramphenicol, respectively. The proposed method might be applied for routine analysis of both drugs in bulk and pharmaceutical formulations. Furthermore, no experimental evidences in favour of adverse pharmaceutical interaction were revealed in their concomitant use.
\end{abstract}

Keywords: Antibiotic; UPLC method; Ciprofloxacin; Chloramphenicol; Pharmaceutical interaction

\section{Introduction}

Ciprofloxacin is a broad spectrum antibiotic and is official in Indian pharmacopoeia, British Pharmacopoeia, United States pharmacopoeia [1]. Ciprofloxacin (CFX) is used clinically for the treatment of respiratory tract infections [2]. Ciprofloxacin is a moderate-spectrum, bacteriolytic, $\beta$-lactam antibiotic in the amino penicillin family used to treat bacterial infections caused by susceptible microorganisms, Grampositive and Gram-negative bacteria. It is usually the drug of choice within the class because it is better-absorbed, following oral administration, than other $\beta$-lactam antibiotics. Ciprofloxacin $\mathrm{HCl}$ is widely used as antibacterial agent for the treatment of infections endocarditis, gastroenteritis, malignant otitis external, respiratory tract infections, urinary tract infections etc. [3].

Ciprofloxacin is one of the most common antibiotics prescribed for children. World Health Organization listed it as the essential medicines needed in a basic health system. They are normally the only penicillins added to feedstuffs at the maximum level of $500 \mathrm{mg} \mathrm{kg}^{-1}$ [4].

Chloramphenicol (CLP) is an effective antibiotic that has widely been used since the 1950s to treat food-producing animals. Chloramphenicol interferes with protein synthesis of many gramnegative and gram-positive bacteria [5] causing toxic effects on humans [6]. The dichloride carbon alpha to the carbonyl group readily undergoes substitution with nucleophiles such as those found on proteins creates toxicity [7].
The main potential human toxicity is ion of red blood cell production in bone marrow is depressed by the chloramphenicol leading to aplastic anemia [5,8]. Which is idiosyncratic and generally fatal? Use of intravenous chloramphenicol being associated with gray baby syndrome newborn infants failed to metabolize chloramphenicol in their body. During breast feeding use of chloramphenicol should be avoided as it passes into breast milk. The use of chloramphenicol in human and veterinary medicine is limited because of the well-known risk of a plastic anemia and carcinogenic properties of CLP [9].

Though no oral formulation of chloramphenicol is available in the U.S. due to its potential toxicity at therapeutic doses it is prescribed for treatment of severe infections in humans. But in the European Union (EU), Canada and United States the use of CLP is banned for meat producing animals and aquaculture. Due to its broad spectrum activity, ease availability and low cost CLP is still recommended to treat seafood products, in optical preparations (ointments and eye drops) for the treatment of bacterial conjunctivitis [10].

The minimum required performance limit (MRPL) for the detection of CLP residues in food of animal origin has been fixed at $0.3 \mu \mathrm{g} \mathrm{kg}^{-1}$ [11] in these considerations for regular monitoring of CLP at residual levels a sensitive and reliable method for the determination is immense needed.

In human and veterinary medicine both ciprofloxacin and chloramphenicol are used due to their antibacterial properties. Both have adverse effect on their overdose nausea, diarrhea, abnormal liver function tests, vomiting, rash mental changes, light-headedness, insomnia, confusion, anxiety. Again, because of the well-known risk of 
Citation: Uddin MN, Das S, Md Mijan NH, Md Al-Amin, Bhuiyan HR (2017) Simultaneous Determination and Mutual Interaction Study of Ciprofloxacin and Chloramphenicol in Concomitant Administration by a New UPLC Method. Pharm Anal Acta 8: 535. doi: $10.4172 / 2153-2435.1000535$

Page 2 of 9

aplastic anemia and carcinogenic properties of CLP, its use in human and veterinary medicine is limited by its toxicity. Therefore, study for their monitoring is immense demand.

Again adverse drug interactions in the concomitant use of ciprofloxacin and chloramphenicol are not well documented. This adverse interaction may effect on their plasma level. Though their simultaneous determination in biosamples is immense important. Attempts have been made to develop new methods the estimation CFX and CLP in bulk, pharmaceutical formulation, foods and biological fluids with good precision, accuracy, linearity and reproducibility.

Chromatographic techniques such as High-Performance Liquid Chromatography (HPLC) with diode array detection [12,13] and Gas Chromatography (GC) with electron capture detection have been used [14,15]. GC-MS methods using either Electron Impact (EI) or Chemical Ionization (CI) have been reported [16,17], but these procedures still require a tedious derivatization step prior to final analysis. Or, HPLC-MS approaches high sensitivity competing to GCMS but still expensive. However, liquid chromatography methods do not require a derivatization step.

It was found that though individually these drugs have been analyzed by many methods, no one is available for their simultaneous estimation in a single run. In this paper UPLC method for simultaneous determination of amoxicillin and chloramphenicol in pharmaceutical formulation has been reported. The proposed method is optimized and validated according to ICH guidelines. This simple, accurate, precise and sensitive method can also be used for the routine analysis of both drugs in mixture without consuming time.

\section{Materials and Methods}

\section{Preparation of calibration curves}

Calibration curves were constructed for seven concentration levels ranging 1.0-10.0 $\mu \mathrm{g} \mathrm{mL}^{-1}$ of each analyte for standard mixture. Peak area ratios of corresponding analytes to the internal standard against their theoretical concentrations were plotted for the preparation of the calibration curves. Curves were fitted by a least squares linear regression to the equation: response ratio $(\mathrm{y})=$ slope $(\mathrm{m}) \times$ concentration(x)+intercept(c). Unknown concentrations of analytes were determined using the calibration equation so obtained.

\section{Chromatographic conditions}

For the optimization chromatographic conditions a standard solution of $5 \mu \mathrm{g} \mathrm{mL}{ }^{-1}$ was used. Reversed-phase Shim-pack XR-ODS $(100 \times 3 \mathrm{~mm}, 1.7 \mu \mathrm{m})$ column and $5 \mathrm{mM} \mathrm{NaH}_{2} \mathrm{PO}_{4}$ as buffer solution throughout the experiment were used for the best separation of both drugs. Special attention has been given to the optimization of mobile phase composition to obtain good resolution at reduced elution time minimizing tailing problems.

In this respect a number of gradient programs were performed to determine the optimum one. To detect the absorption maxima a UV scan of standard solution in the range of $200-400 \mathrm{~nm}$ was done. With respect to sharpness and symmetry of the peaks the best flow rate was optimized. Whole experiment was performed at ambient temperature. The injection volume was $10 \mu \mathrm{L}$. Prior to the analysis the column was equilibrated with the initial ratio of the mobile phase. Prior to use buffer solution was filtered in vacuum using $0.45 \mu \mathrm{m}$ membrane and the mobile phase was degassed by a stream of helium.

\section{Validation parameters}

The ICH $[18,19]$ analytical performance parameters; precision, accuracy, specificity, limit of detection, limit of quantitation, linearity and range, suitability and robustness were studied for the validation of the method.

\section{Results and Discussions}

\section{Chromatography}

The composition of the solvents as mobile phase and its flow rate were optimized as the chromatographic conditions as to elute both drugs with satisfactory peak shape, better separation and a short elution time. With reversed-phase Shim-pack XR-ODS $(100 \times 3.0 \mathrm{~mm}$, $1.7 \mu \mathrm{m})$ column combination of methanol with $5 \mathrm{mM} \mathrm{NaH}_{2} \mathrm{PO}_{4}$ as buffer solution served our intentions best. Peak tailing observed was considerable. The absorption spectra showed maximum absorption wavelengths at $280 \mathrm{~nm}$ and hence it was selected for monitoring as compromised to the both drugs.

On basis of best retention time Rt, peak height and peak width, and resulation factor, Rs optimum mobile phase composition and flow-rate was determined. When the mobile-phase flow-rate was increased Rt and Rs was decreased. For the above consideration the mobile phase mixture of $\mathrm{CH}_{3} \mathrm{OH}$ and $5 \mathrm{mM} \mathrm{NaH} \mathrm{NO}_{4}$ at gradient program equilibrated initially by $50: 50(\mathrm{v} / \mathrm{v})$ (Table 1 ) was delivered at the flow rate $0.2 \mathrm{~mL} \mathrm{~min}$. The method was carried out for the simultaneous detection and quantitation of both drugs representing improved separation in total elution time less than $4 \mathrm{~min}(3.82 \pm 0.03$ minutes).

A representative chromatogram obtained for standard under optimized chromatographic conditions has been shown in Figure 1 which showed appropriate resolution between the drugs of investigation. But both drugs were simultaneously determined without any interferences and influence on their selectivity. System suitability was evaluated from the precision of retention time examined for the within-day (mean value of six measurements, $n=18$ ) and between-day measurements (mean value of three measurements during six days, $\mathrm{n}=54$ ) at 3,5 and $7 \mu \mathrm{gL}^{-1}$ level of drugs, which revealed RSD values of $0.084 \%$. The developed method has been applied to pharmaceutical products for determining the content of investigated drugs. Within-day and between-day precision and accuracy data has been included in Table 2. Results of the validation parameters of proposed UPLC method are presented in Table 3. The estimated values of both drugs contents in pharmaceutical formulations are presented in Tables 4 and 5. 
Citation: Uddin MN, Das S, Md Mijan NH, Md Al-Amin, Bhuiyan HR (2017) Simultaneous Determination and Mutual Interaction Study of Ciprofloxacin and Chloramphenicol in Concomitant Administration by a New UPLC Method. Pharm Anal Acta 8: 535. doi: $10.4172 / 2153-2435.1000535$

Page 3 of 9

\begin{tabular}{|c|c|c|c|c|c|}
\hline \multirow[t]{2}{*}{ Program } & \multirow[t]{2}{*}{ Time (min) } & \multicolumn{2}{|l|}{ Solvent } & \multirow[t]{2}{*}{ Flow rate $\mathrm{mL} / \mathrm{min}$} & \multirow[t]{2}{*}{ R. time (min) } \\
\hline & & $\mathrm{CH}_{3} \mathrm{OH}$ & $5 \mathrm{mM} \mathrm{NaH}{ }_{2} \mathrm{PO}_{4}$ & & \\
\hline \multirow[t]{3}{*}{$A^{*}$} & 0.01 & 50.0 & 50.0 & \multirow[t]{3}{*}{0.20} & \multirow[t]{3}{*}{3.82} \\
\hline & 2.00 & 52.0 & 48.0 & & \\
\hline & $3.00-4.00$ & 56.0 & 44.0 & & \\
\hline \multirow[t]{3}{*}{ B } & 0.01 & 50.0 & 50.0 & \multirow[t]{3}{*}{0.22} & \multirow[t]{3}{*}{3.72} \\
\hline & 2.00 & 52.0 & 48.0 & & \\
\hline & $3.00-4.00$ & 56.0 & 44.0 & & \\
\hline
\end{tabular}

Table 1: Optimum gradient program for the proposed method. ${ }^{\star}$ Program has been followed throughout the experiment.

\begin{tabular}{|c|c|c|c|c|c|c|c|}
\hline \multirow[t]{2}{*}{ Analytes } & \multirow{2}{*}{$\begin{array}{l}\text { Added value } \boldsymbol{\mu g} \\
\mathrm{mL}^{-1}\end{array}$} & \multicolumn{3}{|l|}{ Intraday analysis } & \multicolumn{3}{|l|}{ Inter day analysis } \\
\hline & & Found value $\mu \mathrm{g} \mathrm{mL}^{-1}$ & RSD (\%) & Recovery (\%) & Found value $\mu \mathrm{g} \mathrm{mL}^{-1}$ & RSD (\%) & Recovery (\%) \\
\hline \multirow[t]{6}{*}{ CFX } & 0.5 & $0.53 \pm 0.06$ & 0.40 & 106.3 & $0.52 \pm 0.07$ & 2.34 & 105.6 \\
\hline & 1 & $1.02 \pm 0.09$ & 0.86 & 101.7 & $1.01 \pm 0.08$ & 2.29 & 100.8 \\
\hline & 2 & $2.04 \pm 0.10$ & 2.00 & 101.8 & $2.04 \pm 0.11$ & 2.65 & 102.3 \\
\hline & 3 & $2.95 \pm 0.09$ & 1.25 & 98.5 & $2.97 \pm 0.09$ & 1.08 & 99.1 \\
\hline & 5 & $5.01 \pm 0.11$ & 1.15 & 100.3 & $5.01 \pm 0.11$ & 1.10 & 100.4 \\
\hline & 10 & $10.01 \pm 0.22$ & 1.57 & 100.2 & $10.01 \pm 0.22$ & 1.48 & 100.2 \\
\hline \multirow[t]{6}{*}{ CLP } & 0.5 & $0.52 \pm 0.02$ & 0.41 & 104.0 & $0.53 \pm 0.09$ & 0.49 & 106.0 \\
\hline & 1 & $1.04 \pm 0.09$ & 1.57 & 104.2 & $1.04 \pm 0.09$ & 1.41 & 104.4 \\
\hline & 2 & $1.97 \pm 0.11$ & 1.69 & 98.5 & $1.99 \pm 0.12$ & 2.24 & 99.5 \\
\hline & 3 & $2.92 \pm 0.14$ & 2.24 & 97.3 & $2.88 \pm 0.15$ & 2.84 & 96.2 \\
\hline & 5 & $5.03 \pm 0.12$ & 0.98 & 100.6 & $5.04 \pm 0.13$ & 1.13 & 100.8 \\
\hline & 10 & $10.01 \pm 0.15$ & 0.71 & 100.2 & $9.99 \pm 0.15$ & 0.72 & 99.9 \\
\hline
\end{tabular}

Table 2: Summarizes within-day and between-day precision and accuracy data.

\begin{tabular}{|c|c|c|}
\hline Validation Parameters & (CFX) & (CLP) \\
\hline Measurement wavelength (nm) & \multicolumn{2}{|l|}{280} \\
\hline Linear range $\left(\mu \mathrm{g} \mathrm{mL}^{-1}\right)$ & \multicolumn{2}{|l|}{$0.20-10$} \\
\hline Linearity equation & $y=2.8915 \times-0.1764$ & $y=8.1355 \times-0.6414$ \\
\hline Correlation coefficient ( $r$ ) & 0.9997 & 0.9997 \\
\hline $\begin{array}{l}\text { Relative standard deviation (\% RSD) } \\
\text { Intraday } \\
\text { Inter day }\end{array}$ & $\begin{array}{l}0.40-2.00 \\
1.08-2.65\end{array}$ & $\begin{array}{l}0.41-2.24 \\
0.49-2.84\end{array}$ \\
\hline $\begin{array}{l}\text { Recovery (\% R) } \\
\text { Intraday } \\
\text { Inter day }\end{array}$ & $\begin{array}{l}98.5-101.7 \\
99.1-105.6\end{array}$ & $\begin{array}{l}97.3-104.2 \\
96.2-106.0\end{array}$ \\
\hline Limit of detection, LOD $\left(\mu \mathrm{g} \mathrm{mL}^{-1}\right)$ & 0.025 & 0.08 \\
\hline Limit of quantification, LOQ $\left(\mu \mathrm{g} \mathrm{mL}^{-1}\right)$ & 0.02 & 0.07 \\
\hline
\end{tabular}

Table 3: Validation performance of the proposed UPLC method. 
Citation: Uddin MN, Das S, Md Mijan NH, Md Al-Amin, Bhuiyan HR (2017) Simultaneous Determination and Mutual Interaction Study of Ciprofloxacin and Chloramphenicol in Concomitant Administration by a New UPLC Method. Pharm Anal Acta 8: 535. doi: $10.4172 / 2153-2435.1000535$

Page 4 of 9

\begin{tabular}{|c|c|c|c|c|c|}
\hline \multirow{2}{*}{ Drug Name (Tablet) } & \multicolumn{2}{|c|}{ Conc. $\mu \mathrm{g} \mathrm{mL^{-1 }}$} & \multirow[t]{2}{*}{ RSD } & \multirow[b]{2}{*}{$\%$ Recovery } & \multirow[b]{2}{*}{ Mean R (\%) } \\
\hline & Added & Found & & & \\
\hline \multirow{3}{*}{ Ciprozid DS } & 1 & $0.76 \pm 0.03$ & 1.50 & 76.30 & \multirow[b]{3}{*}{75.00} \\
\hline & 3 & $2.27 \pm 0.10$ & 1.62 & 75.70 & \\
\hline & 5 & $3.64 \pm 0.06$ & 0.59 & 72.99 & \\
\hline \multirow{3}{*}{ Ciprocin } & 1 & $1.01 \pm 0.01$ & 0.64 & 101.48 & \multirow[b]{3}{*}{98.24} \\
\hline & 3 & $2.92 \pm 0.03$ & 0.44 & 97.34 & \\
\hline & 5 & $4.79 \pm 0.10$ & 1.45 & 95.89 & \\
\hline \multirow{3}{*}{ Cipro-A } & 1 & $1.08 \pm 0.01$ & 0.27 & 108.62 & \multirow[b]{3}{*}{101.93} \\
\hline & 3 & $2.97 \pm 0.07$ & 0.91 & 99.03 & \\
\hline & 5 & $4.90 \pm 0.07$ & 0.52 & 98.13 & \\
\hline \multirow{3}{*}{ Neofloxin } & 1 & $0.56 \pm 0.01$ & 0.35 & 56.86 & \multirow[b]{3}{*}{54.09} \\
\hline & 3 & $1.66 \pm 0.20$ & 5.13 & 55.63 & \\
\hline & 5 & $2.48 \pm 0.06$ & 0.92 & 49.79 & \\
\hline \multirow{3}{*}{ Bactin } & 1 & $0.77 \pm 0.03$ & 1.86 & 77.33 & \multirow[b]{3}{*}{78.39} \\
\hline & 3 & $2.48 \pm 0.10$ & 2.10 & 82.92 & \\
\hline & 5 & $3.74 \pm 0.01$ & 0.04 & 74.91 & \\
\hline \multirow{3}{*}{ Flontin } & 1 & $0.54 \pm 0.01$ & 0.19 & 54.51 & \multirow[b]{3}{*}{52.71} \\
\hline & 3 & $1.51 \pm 0.02$ & 0.61 & 50.64 & \\
\hline & 5 & $2.64 \pm 0.05$ & 0.78 & 52.99 & \\
\hline \multirow{3}{*}{ Aprocin } & 1 & $0.68 \pm 0.01$ & 0.22 & 68.60 & \multirow[b]{3}{*}{66.59} \\
\hline & 3 & $2.05 \pm 0.1$ & 3.29 & 68.33 & \\
\hline & 5 & $3.14 \pm 0.03$ & 0.38 & 62.85 & \\
\hline \multirow{3}{*}{ Ciprox } & 1 & $0.58 \pm 0.01$ & 0.34 & 58.34 & \multirow[b]{3}{*}{56.19} \\
\hline & 3 & $1.69 \pm 0.05$ & 1.26 & 56.62 & \\
\hline & 5 & $2.68 \pm 0.02$ & 0.31 & 53.60 & \\
\hline
\end{tabular}

Table 4: Determination of ciprofloxacin in pharmaceutical formulations by the proposed method.

\begin{tabular}{|c|c|c|c|c|}
\hline \multirow{2}{*}{ Formulation } & Added value & Exp. conc. & \multirow{2}{*}{ RSD\% } & Mean R\% \\
\hline & \multicolumn{2}{|l|}{$\mu \mathrm{g} \mathrm{mL}^{-1}$} & & \\
\hline \multicolumn{5}{|l|}{ Eye drops } \\
\hline \multirow{3}{*}{ A-Phenicol } & 3 & $3.13 \pm 0.03$ & 1.06 & \multirow{3}{*}{101.22} \\
\hline & 5 & $5.18 \pm 0.04$ & 0.70 & \\
\hline & 7 & $6.69 \pm 0.07$ & 1.04 & \\
\hline
\end{tabular}


Citation: Uddin MN, Das S, Md Mijan NH, Md Al-Amin, Bhuiyan HR (2017) Simultaneous Determination and Mutual Interaction Study of Ciprofloxacin and Chloramphenicol in Concomitant Administration by a New UPLC Method. Pharm Anal Acta 8: 535. doi: $10.4172 / 2153-2435.1000535$

Page 5 of 9

\begin{tabular}{|c|c|c|c|c|}
\hline \multirow{3}{*}{ Cloram } & 3 & $2.75 \pm 0.07$ & 2.49 & \multirow{3}{*}{91.25} \\
\hline & 5 & $4.53 \pm 0.14$ & 3.12 & \\
\hline & 7 & $6.40 \pm 0.02$ & 0.39 & \\
\hline \multirow{3}{*}{ Ocutrex } & 3 & $2.82 \pm 0.05$ & 1.79 & \multirow{3}{*}{86.80} \\
\hline & 5 & $4.44 \pm 0.05$ & 1.16 & \\
\hline & 7 & $5.43 \pm 0.02$ & 0.36 & \\
\hline \multirow{3}{*}{ ICOL } & 3 & $2.60 \pm 0.69$ & 2.80 & \multirow{3}{*}{88.91} \\
\hline & 5 & $4.74 \pm 0.05$ & 1.00 & \\
\hline & 7 & 5.973914 & 1.56 & \\
\hline \multirow{3}{*}{ Chlorophen } & 3 & $2.88 \pm 0.03$ & 0.90 & \multirow{3}{*}{88.24} \\
\hline & 5 & $4.47 \pm 0.07$ & 1.67 & \\
\hline & 7 & $5.56 \pm 0.05$ & 0.96 & \\
\hline \multirow{3}{*}{ Optaphenicol } & 3 & $1.65 \pm 0.09$ & 5.18 & \multirow{3}{*}{47.70} \\
\hline & 5 & $2.32 \pm 0.08$ & 3.42 & \\
\hline & 7 & $2.93 \pm 0.02$ & 0.52 & \\
\hline \multirow{3}{*}{ Supraphen } & 3 & $1.92 \pm 0.03$ & 1.33 & \multirow{3}{*}{71.75} \\
\hline & 5 & $3.68 \pm 0.07$ & 1.81 & \\
\hline & 7 & $5.43 \pm 0.02$ & 0.44 & \\
\hline \multirow{3}{*}{ Optabac } & 3 & $1.99 \pm 0.05$ & 2.45 & \multirow{3}{*}{74.59} \\
\hline & 5 & $3.84 \pm 0.03$ & 0.82 & \\
\hline & 7 & $5.64 \pm 0.01$ & 0.15 & \\
\hline \multirow{3}{*}{ SQ mycetine } & 3 & $3.08 \pm 0.01$ & 0.46 & \multirow{3}{*}{98.43} \\
\hline & 5 & $4.76 \pm 0.15$ & 3.25 & \\
\hline & 7 & $6.82 \pm 0.09$ & 1.29 & \\
\hline \multirow{3}{*}{ Opsophenicol } & 3 & $2.50 \pm 0.13$ & 5.47 & \multirow{3}{*}{87.20} \\
\hline & 5 & $4.37 \pm 0.06$ & 1.45 & \\
\hline & 7 & $6.35 \pm 0.08$ & 1.34 & \\
\hline \multicolumn{5}{|l|}{ Ointment } \\
\hline \multirow{3}{*}{ Supraphen } & 3 & $2.88 \pm 0.09$ & 3.12 & \multirow{3}{*}{97.89} \\
\hline & 5 & $4.93 \pm 0.17$ & 3.42 & \\
\hline & 7 & $6.95 \pm 0.27$ & 3.80 & \\
\hline \multicolumn{5}{|l|}{ Injection } \\
\hline \multirow{3}{*}{ Optichlor } & 3 & $1.82 \pm 0.02$ & 0.57 & \multirow{3}{*}{67.96} \\
\hline & 5 & $3.46 \pm 0.06$ & 0.91 & \\
\hline & 7 & $5.17 \pm 0.06$ & 0.64 & \\
\hline
\end{tabular}

Table 5: Determination of chloramphenicol in pharmaceutical formulations by the proposed method. 
Citation: Uddin MN, Das S, Md Mijan NH, Md Al-Amin, Bhuiyan HR (2017) Simultaneous Determination and Mutual Interaction Study of Ciprofloxacin and Chloramphenicol in Concomitant Administration by a New UPLC Method. Pharm Anal Acta 8: 535. doi: $10.4172 / 2153-2435.1000535$

Page 6 of 9

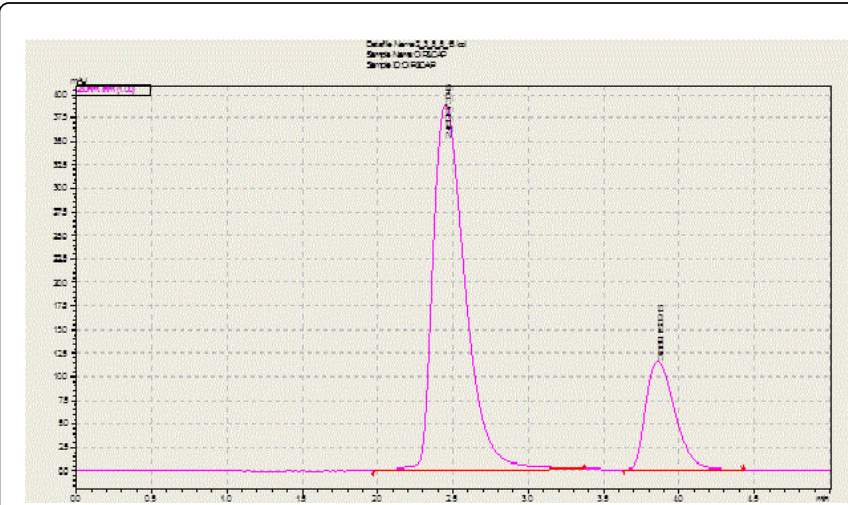

Figure 1: Typical UPLC chromatogram of the two examined drugs $\left(2 \mu \mathrm{g} \mathrm{mL}^{-1}\right)$ in standard. Chromatographic conditions are described in text. Peaks: $2.45 \mathrm{~min}$ (CFX), $3.85 \mathrm{~min}$ (CLP).

\section{Method validation}

For the validation of the proposed method parameters, linearity, selectivity, extraction recovery, precision, accuracy, stability and robustness were calculated. The UPLC method developed herein used a simple mobile phase. It provided a rapid quality control determination of both drugs in pharmaceutical formulations.

\section{Linearity}

The calibration curves constructed for standard using working concentration at levels $3.0,5.0,7.0,9.0,10.0 \mu \mathrm{g} \mathrm{mL}^{-1}$ of each drug. Each concentration was analyzed in triplicate and calibration curves were constructed by plotting the peak area ratio of drug to the internal standard versus nominal concentrations of the analytes. Least square linear regression analysis of the data gave slope, intercept, and correlation coefficient or coefficient of determination. Calibration equations are $y=2.8915 \times-0.1764$ for CFX and $y=8.1355 \times-0.6414$ for CLP determination. The calibration curves were linear in the range of 0.2-10 $\mu \mathrm{g} \mathrm{mL} \mathrm{m}^{-1}$ for both CFX and CLP. The coefficients of determination $\left(\mathrm{r}^{2}\right)$ were 0.9997 for both drugs. Figures 2 and 3 show the calibration curves for the determination of ciprofloxacin and chloramphenicol, respectively.

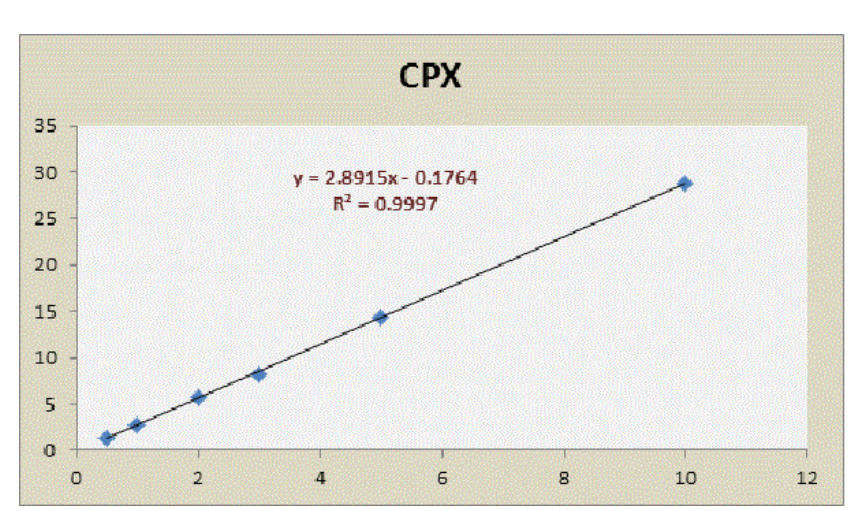

Figure 2: Calibration curve for the determination of ciprofloxacin.

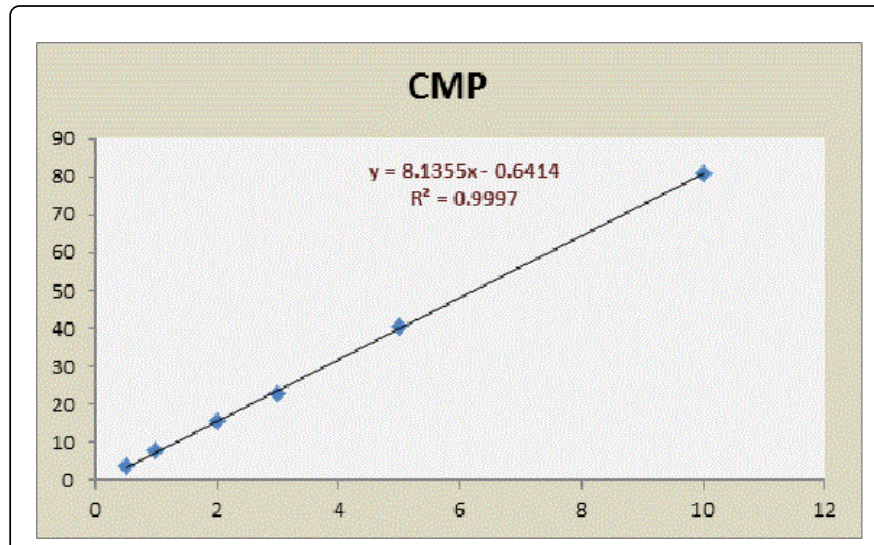

Figure 3: Calibration curve for the determination of chloramphenicol.

\section{Recovery/accuracy}

Aliquots of $10 \mu \mathrm{L}$ assay solutions at three concentration levels were analysed by UPLC method and triplicate measurements were recorded for each. The nominal contents of the drug in each solution were calculated using the regression equations. The results were expressed as percentage content present in the samples as [mean found concentration/theoretical concentration] $\times 100$. The mean results of the within-day assay at three concentrations $(n=6)$ was $97-107 \%$ and that of between-day assay at six different days was $98-106 \%$. Results obtained by the validated method indicated high accuracy of both drugs.

\section{Precision}

The precision was determined by calculating the Standard Deviation (SD) and the Relative Standard Deviation (RSD) for the replicate measurements between nominal and calculated concentrations of each level. Intraday repeatability was determined in six replicates at five assay levels of standard within day. The procedure was repeated to determine inter-day repeatability on six consecutive days at same levels in standard solutions. The relative standard deviations (RSD) obtained for the within-day assay was in the range $0.40-2.00$ for CFX and 0.78-2.24 for CLP. The corresponding values for Between-day assay was in the range $1.5-7.1 \%$ for CFX and $1.3-5.5 \%$ for CLP. These indicated the excellent precision of the method. The results of the within-day and between-day recovery and precision analysis are presented in Table 2.

\section{Sensitivity}

Limit of Detection (LOD and the Limit of Quantitation (LOQ) were calculated by data analysis by ANOVA program with acceptable precision and accuracy to test the sensitivity of the method. These were calculated from calibration graph by the formula, $\mathrm{LOD}=3 \cdot \mathrm{Sxy} / \mathrm{a}$ and $\mathrm{LOQ}=10 \cdot$ Sxy/a. Where, Sxy=Standard deviation of the response and $\mathrm{a}=$ slope of the calibration curve. The LOD and LOQ were 0.025 and $0.08 \mu \mathrm{g} \mathrm{mL}^{-1}$ for CFX and 0.020 and $0.07 \mu \mathrm{g} \mathrm{mL}^{-1}$ for CLP, respectively. These results indicated that method was sensitive enough for therapeutic assay. 
Citation: Uddin MN, Das S, Md Mijan NH, Md Al-Amin, Bhuiyan HR (2017) Simultaneous Determination and Mutual Interaction Study of Ciprofloxacin and Chloramphenicol in Concomitant Administration by a New UPLC Method. Pharm Anal Acta 8: 535. doi: $10.4172 / 2153-2435.1000535$

Page 7 of 9

\section{Specificity}

There was no peak in the same retention times that might be present for potential impurities or degradation products. Determination of the drugs free of interferences from potential impurities and any degradation products demonstrated the excellent specificity of the method. Results indicate the high specificity of the method. Method might be used in stability assay and routine analysis of the both investigated drugs.

\section{Robustness}

Robustness of the method has been evaluated by varying method parameters as given in Table 1 such as flow rate, gradient program, concentration of buffer. The percent recoveries were excellent under most conditions, and remained unaffected by small deliberate changes of experimental parameters though retention time and resolution was decreased as expected. Therefore it is concluded that the method was robust.

\section{System suitability}

Replicate measurements of each of three concentration levels including within- and between-day analyses were performed for the system suitability assessment. Precision of retention time and peak area ratios was investigated to evaluate the system suitability. RSD of the peak area ratios $1.07-1.71 \%$ and that of retention time $0.47-1.33 \%$ indicates excellent suitability of the system.

\section{Column efficiency}

For a representative chromatogram by the relations: retention factor, $\mathrm{k}=\mathrm{tR}-\mathrm{t} 0 / \mathrm{t} 0$, separation factor, $\alpha=\mathrm{tR}_{2}-\mathrm{t}_{0} / \mathrm{tR}_{1}-\mathrm{t}_{0}$, resolution factor, $\mathrm{R}=2$ $\left(\mathrm{tR}_{2}-\mathrm{tR}_{1}\right) /\left(\mathrm{w}_{2}+\mathrm{w}_{2}\right)$, theoretical plate number, $\mathrm{N}=16(\mathrm{tR} / \mathrm{w}) 2$ and tailing or asymmetry factor, $\mathrm{Tf}=(\mathrm{a}+\mathrm{b}) / 2 \mathrm{a}$ have been calculated as the column efficiency parameters. Where, $t_{0}, t_{1}$ and $t_{2}$ are the retention times and $\mathrm{w}_{1}$ and $\mathrm{w}_{2}$ the baseline peak width of successive peaks. The calculated values; retention factor, $\mathrm{k}=1.1-4.8$, separation factor, $\alpha=1.1-1.8$, resolution factor, $\mathrm{Rs}=0.7-4.3$, theoretical plate number, and tailing factor, $\mathrm{T}_{\mathrm{f}}=1.0-1.5$ showed the Excellency of the column performance.

\section{Stability}

The freshly prepared solutions at room temperature and the solutions stored in a refrigerator at both $4^{\circ} \mathrm{C}$ for 30 days were analyzed for long-term assay. Each sample was analyzed for intact compounds once a week. Recovery and RSD of the stored samples were calculated and compared to that of freshly prepared samples. Stability of both CFX and CLP in methanol was checked during seven days at room temperature stored in dry and dark place and refrigerated at $4^{\circ} \mathrm{C}$ and $-20^{\circ} \mathrm{C}$. Recoveries of methanolic solution of each compound were $\geq 99.6 \%$ up to one week stored at room temperature. Gradual decrease was appeared after 10 days stored at $4^{\circ} \mathrm{C}$. It was observed that there was no degradation product and the drug was stable at $-20^{\circ} \mathrm{C}$ for at least 60 days. Figures 4 and 5 indicated the possibility of using the samples over a period of 30 days at refrigerator without degradation.

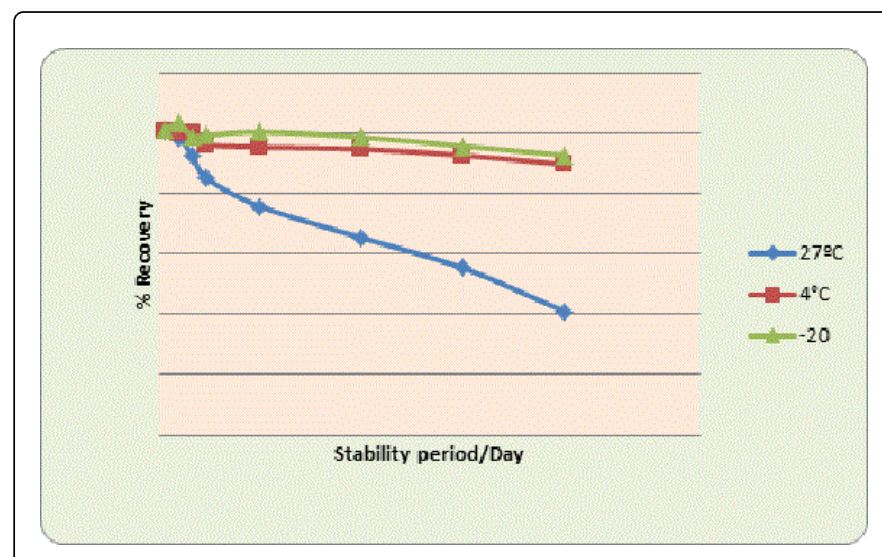

Figure 4: Long term stability graph for Ciprofloxacin.

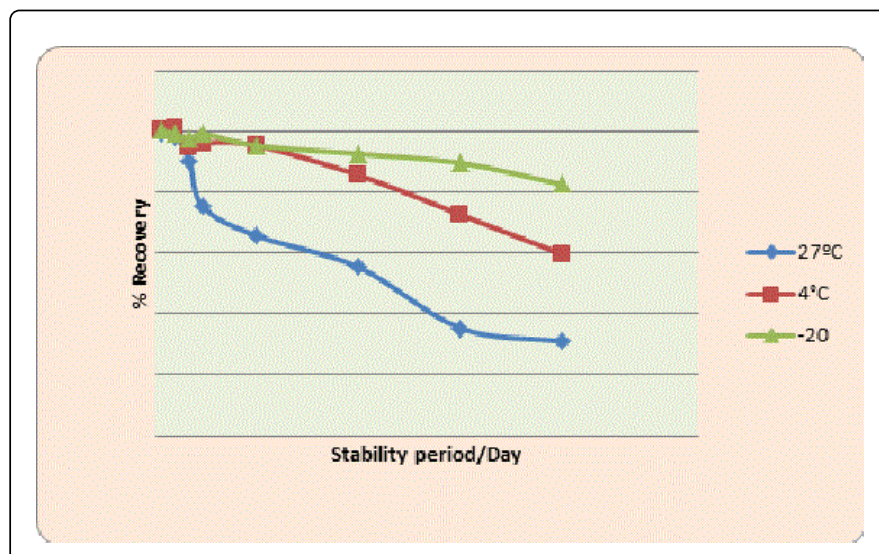

Figure 5: Long term stability graph for Chloramphenicol.

\section{Drug interaction in concomitant application}

Ciprofloxacin have an impact only on reproducing organisms, so they should not be combined with bacteriostatic antibiotics, such as chloramphenicol. Chloramphenicol may interfere with the bactericidal effects of Ciprofloxacin. This has been demonstrated in vitro; however, the clinical significance of this interaction is not well documented.

Concomitant administration with bacteriostatic antibiotics e.g., chloramphenicol or chemotherapeutics should be avoided as in vitro antagonism may occur due to their different mechanisms of action. There is a possibility that the antibacterial action of amoxicillin could be antagonized on coad ministration with chloramphenicol. It may decrease the plasma level of estrogens and progesterone, and may reduce the efficacy of oral contraceptives. However, the clinical significance of this interaction is not well documented.

The was by Yosmar et al. [18] investigated the drug interaction of amoxicillin and chloramphenicol in their concomitant use. No pharmaceutical interaction was still reported for amoxicillin and chloramphenicol during their concomitant administration. No study was performed for the drug interaction in their concomitant use of ciprofloxacin and chloramphenicol. Our present study showed that both drugs have been determined simultaneously in their mixture free of interference from potential impurities and degradation products by the absence of any peak in the same retention times. No evidences of 
Citation: Uddin MN, Das S, Md Mijan NH, Md Al-Amin, Bhuiyan HR (2017) Simultaneous Determination and Mutual Interaction Study of Ciprofloxacin and Chloramphenicol in Concomitant Administration by a New UPLC Method. Pharm Anal Acta 8: 535. doi: $10.4172 / 2153-2435.1000535$

Page 8 of 9

degradation or interferences was detected our present condition with in study range or retention time. From the chromatogram it is evident no drug interactions or online derivatization has been occurred in their combined determination or with their formulation excipients, since there was no peaks on their retention times. Acceptable precision (RSD) of peak area for 25 the measurements at three concentration levels and \% recovery of drugs were investigated. RSD for the elution time for both drugs also found to be as $3.84 \pm 0.03 \mathrm{~min}$. Both evidences proved that there is no drug interaction in their combined mixture.

Investigation concluded that drug interaction doesn't suppose due to physicochemical interaction. No physical and chemical reactions occur between drugs that might alter or eliminate the pharmacological activity of both drugs. The drug interactions might be due to the pharmacodynamic interaction in concomitant use of ciprofloxacin and chloramphenicol. Pharmacodynamic interaction may reduce the efficacy of other drugs. This adverse interaction could reduce plasma level of ciprofloxacin decreasing its efficacy. Further research is required for the confirmation of this interaction. The interaction could cause antagonistic effect as the chloramphenicol works by inhibiting bacterial protein synthesis and could change the active growth of bacterial colonies to be static. This could cause the bactericidal effect of ciprofloxacin to be obstructed and bacterial killing becomes slower.

\section{Application to pharmaceutical formulations}

The UPLC method developed here was applied to the 1.0, 3.0, and $5.0 \mu \mathrm{g} \mathrm{mL}^{-1}$ concentration levels of drugs from their pharmaceutical products for determining the content of CFX and CLP. Figure 6 is typical UPLC chromatogram of the two drugs at $7 \mu \mathrm{g} \mathrm{mL}^{-1}$ concentration level under the optimized conditions.

The percentage recoveries and the RSD values of measurements are tabulated in Tables 4 and 5. Recovery was almost same as that of levelled values. In case of eye drops recovery was lower than levelled values for all products. Moreover determination was free of interference from degradation products and no interference from the sample excipients could be observed at this detection wavelength, indicating the high specificity of the method.

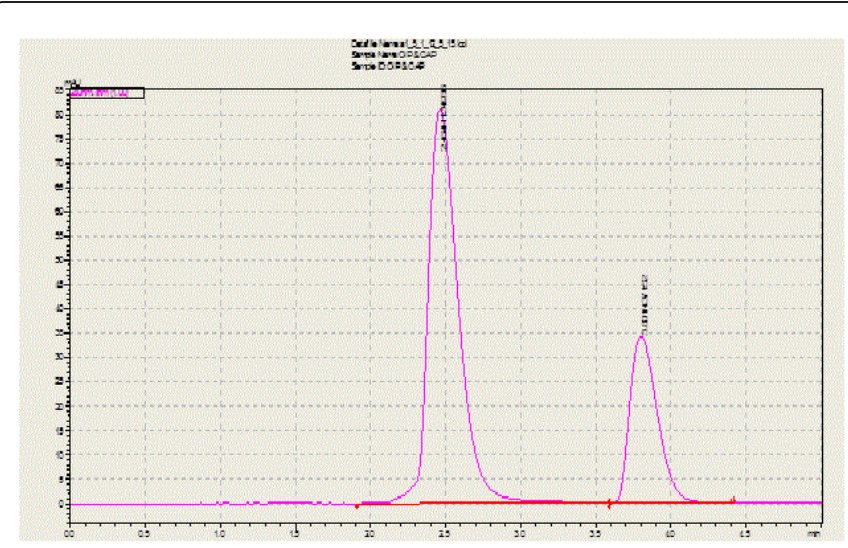

Figure 6: Typical UPLC chromatogram of the two examined drugs $\left(5 \mu \mathrm{g} \mathrm{mL}^{-1}\right)$ in drug formulation. Chromatographic conditions are described in text. Peaks: $2.46 \mathrm{~min}$ (CFX), $13.80 \mathrm{~min}$ (CLP).

\section{Conclusion}

The proposed work provides a fast, precise, sensitive, accurate, linear, robust, simple and rugged UPLC assay method with stability indicating potential for these two drugs in mixture or alone. For the proposed method both the drugs gave well define peaks. They were well separated. The validation data demonstrate good precision and accuracy, which prove the reliability of the proposed method. The reproducibility, repeatability and accuracy of the proposed method were found to be satisfactory as indicated by low values of standard deviation and relative standard deviation in comparison to previous methods. The percent recovery obtained indicates non-interference from the excipients used in the formulations. This study demonstrates the applicability of the proposed method for the potency determination of ciprofloxacin and chloramphenicol in bulk drug and capsule, injection, and granule formulations. The method can be successfully used for routine quality control of the raw material, formulations and dissolution studies and stability assays and offers advantages in speed, simplicity, and reliability. The significant advantage of the developed method is the fact that through the lack of a fluorescence and MS detector, UV-detection represents a good alternative choice. Another advantage is to determine both drugs by $4.00 \mathrm{~min}$. To the best of our knowledge no method provides their fast determination with precision and accuracy or no methods are available for their simultaneous determination rather than alone. Furthermore, it is found that drug interaction doesn't suppose due to physicochemical interaction. Adverse drug interactions are supposed to be due to pharmacodynamic interaction rather than pharmaceutical interaction in the concomitant use of ciprofloxacin and chloramphenicol. Method might be applied for their simultaneous determination in plasma samples in pharmacodynamic interaction study.

\section{References}

1. Sneha Jansari K, Nirav Patel R, Nikita Patel N, Hemant Desai T (2012) Development and Validation of stability indicating method for simultaneous estimation of ciprofloxacin and tinidazole using rp-uplc method. IOSR J Pharm 2: 12-17.

2. Khadabadi SS, Devkar MG (2013) A validated RP-HPLC method for the simultaneous determinarion of Metronidazole and Ciprofloxacin hydrochloride in pharmaceuticals dosage form, Int J Pharm Res 4: 4736-4740.

3. Bushra U, Md. Huda N, Mostafa M, Md. Sultan Z, Rahman A (2013) Study of forced degradation of ciprofloxacin $\mathrm{HCl}$ indicating stability using RP_HPLC method. Der Pharma Chemica 5: 132-137.

4. Injac R, Kocevar N, Strukelj B (2009) Optimized method for determination of amoxicillin, ampicillin, sulfamethoxazole, and sulfacetamide in animal feed by micellar electrokinetic capillary chromatography and comparison with high-performance liquid chromatography. Croat Chem Acta 82: 685-694.

5. Pensabene JW, Fiddler W (1999) Isolation of Chloramphenicol from whole eggs by supercritical fluid extraction with in-line collection. J AOAC Int 82: 13334-1339.

6. Roybal JE (1998) Chloramphenicol and related drugs, analytical procedures for drug residues in food of animal origin, Science Technology System, Sacramento, CA, pp: 227-260.

7. Baker BR (1967) Design of active-site-directed irreversible enzyme inhibitors. J Med Chem 10: 1196.

8. Clark SB, Barrell RA, Nandrea JM, Geisler CA, Hurlbut JA (1991) Determination of chloramphenicol residue in raw milk by gas-liquid chromatography with electron-capture detector, Laboratory Information Bulletin. 
Citation: Uddin MN, Das S, Md Mijan NH, Md Al-Amin, Bhuiyan HR (2017) Simultaneous Determination and Mutual Interaction Study of Ciprofloxacin and Chloramphenicol in Concomitant Administration by a New UPLC Method. Pharm Anal Acta 8: 535. doi: $10.4172 / 2153-2435.1000535$

Page 9 of 9

9. www.fda.gov/bbs/topics/NEWS/2002/New00815.html

10. Pfenning AP, Roybal JE, Rupp HS, Turnipseed SB, Gonzales SA (2000) Simultaneous determination of residues of chloramphenicol, florfenicol, florfenicol amine, and thiamphenicol in shrimp tissue by gas chromatography with electron capture detection. J AOAC Int 83: 26-30.

11. (2003) Commission Decision of 13 March 2003 amending Decision 2002/657/EC as regards the setting of minimum required performance limits (MRPLs) for certain residues in food of animal origin. 2003/181/EC

12. Abreu LR, Ortiz RA (2003) HPLC determination of amoxicillin comparative bioavailability in healthy volunteers after a single dose administration. J Pharm Sci 6: 223230.

13. Zarapkar SS, Rane SH (2000) Reverse phase high performance liquid chromatographic determination of amoxicillin and ambroxol hydrochloride in tablets. Indian Drugs 37: 246250.

14. Keukens HJ, Aerts MML, Traag WA, Nouws JFM, de Ruig WG (1992) J Assoc Off Anal Chem Int 75: 245 .
15. Borner S, Fry H, Balizs G, Kroker R (1995) J Assoc Off Anal Chem Int78: 1153.

16. Nagata T, Oka H (1996) Detection of residual chloramphenicol, florfenicol, and thiamphenicol in yellowtail fish muscles by capillary gas chromatography-mass spectrometry. J Agric Food Chem 44: 1280.

17. (1996) Validation of Analytical Procedures: Text and Methodology Q2 (R1). ICH Harmonized Tripartite, International Conference on Harmonisation, Geneva, Switzerland.

18. Yosmar R, Arifin H, Darwin D, Yani FF (2013) Identification of adverse drug interactions in pediatric patients of lower respiratory tract infection diseases at Children's Ward of Dr. M. Djamil Hospital, Padang-Indonesia. Int J Pharm Teach Pract 4: 662-665.

19. Uddin MN (2016) Simultaneous determination of amoxicillin and chloramphenicol and their drug interaction study by the validated UPLC method. J Taibah Univ Sci 10: 755-765. 